\title{
Mammography screening in three Finnish residential areas: comprehensive population- based study of breast cancer incidence and incidence-based mortality 1976-2009
}

\author{
I Parvinen*,1, S Heinävaara ${ }^{2}$, A Anttila ${ }^{2}$, H Helenius ${ }^{3}$, P Klemi ${ }^{4}$ and L Pylkkänen ${ }^{5,6}$ \\ ${ }^{1}$ University of Turku, Medical Faculty, University of Turku, FI-20014 Turku, Finland; ${ }^{2}$ Finnish Cancer Registry, Unioninkatu 22, \\ Fl-00130 Helsinki, Finland; ${ }^{3}$ University of Turku, Medical Faculty, Department of Biostatistics, University of Turku, Fl-20014 Turku, \\ Finland; ${ }^{4}$ University of Turku, Medical Faculty, Department of Pathology, University of Turku, Fl-20014 Turku, Finland; ${ }^{5}$ University of \\ Turku, Medical Faculty, Department of Clinical Oncology, University of Turku, Fl-20014 Turku, Finland and ${ }^{6}$ Cancer Society of \\ Finland, Unioninkatu 22, Fl-00130 Helsinki, Finland
}

\begin{abstract}
Background: The aim of this study was to evaluate the effectiveness of a large-scale screening programme for breast cancer (BC) in Turku, Finland. Incidence and incidence-based mortality (IBM) figures were compared with the areas applying different screening policies.
\end{abstract}

Methods: Deaths and person-time of women aged 40-84 were assessed for the period 1976-1986 (prescreening era) and the periods 1987-1997 and 1998-2009 (screening periods) using incidence and IBM by age at diagnosis and at death. There was a total of 40.7 million women-years, 83497 invasive BCs obtained from the Finnish Cancer Registry; 17508 BC deaths were linked with the data from Statistics Finland.

Results: In Turku, a significant (> 20\%) reduction in IBM occurred during 1987-2009 among women aged 60-74 years at diagnosis compared with Helsinki (IBMRR: 0.75, 95\% Cl: 0.57-1.00), and in women aged 75-84 years at death compared with the rest of Finland (IBMRR: $0.72,95 \% \mathrm{Cl}: 0.53-0.96)$.

Conclusions: The wide mammography screening programme in Turku was effective in decreasing BC mortality in the elderly age groups. These results support the implementation of BC screening from age 50 up to 74 years.

Breast cancer $(\mathrm{BC})$ mortality figures have declined over the two last decades (Coleman et al, 2011). This mortality reduction is considered to be due to improved treatment, screening and system efficiency (Autier et al, 2010), and depends on how systematically screening is implemented and accepted by the target population and on the efficiency of the linkage between diagnosis and treatment.

The UK Panel on Breast Cancer screening (Independent UK Panel on Breast Cancer Screening, 2012) concluded that routine breast cancer screening at 3-year intervals, as practiced in the United Kingdom, leads to a $20 \%$ relative reduction in the risk of death compared with no screening. There are, nevertheless, conflicting opinions on the value of mammography screening (Bleyer and Welch, 2012; Gøtzsche et al, 2012).

The ultimate role of mammography screening needs to be assessed. For this more, reliable and updated study results are needed (Tabár et al, 2011; Monticciolo and Monsees, 2013). Finland is an ideal candidate for population-based mammography 
screening studies: treatment guidelines and standards are consistent throughout the country and are adhered to health registers and reporting methods are reliable, comprehensive and up to date.

The city of Turku, Finland, has screened all women aged 40-74 years since 1987. No other Finnish municipality screened regularly women aged 40-49 and 60-74 at that time. In other residential areas of Finland, BC screening was started on 1987 for women aged 50-59 years with gradually increasing coverage.

The main objective of the current study was to investigate the effectiveness of the $\mathrm{BC}$ screening programme regarding $\mathrm{BC}$ incidence and incidence-based mortality (IBM) among women aged 40-84 years. We had a special interest in the age groups 40-49 and 60-74, since there are global only a few long-term follow-up studies that have focused on the age groups younger than 50 years or older than 69 years (Tabár et al, 2011; Broeders et al, 2012; Nickson et al, 2012; Moss et al, 2012). Here, we describe the crude and adjusted incidence and mortality patterns in three residential areas, Turku, Helsinki, and the rest of Finland, for mammography screens aged 40-84 years. Effectiveness was evaluated by examining the results of the different invitation policies in the city of Turku and the two other residential areas.

\section{MATERIALS AND METHODS}

National BC mammography screening programmes by invitation began in 1987 in Finland. Since 1992, all women aged 50-59 years receive screening invitations every second year. The screening in Turku targeted female inhabitants aged 40-74 years. In the reference areas only women aged 50-59 (Helsinki) and in a few municipalities (in the rest of Finland) women aged 60-64 were included and, irregularly, women aged 65-69 years (Sarkeala, 2008; Sarkeala et al, 2008a).

During the early 1990s, the nationwide coverage of invitations (aged 50-59) was nearly 100\% (Finnish Cancer Registry, 2014). In Helsinki and in most municipalities in RoF, women aged 60-74 were not invited before the year 2007. Since then the upper age of invitation has gradually been raised to 69 years in the national programme, and currently it covers the whole country. In Turku, women aged 40-49 years were invited at modified invitation intervals from 1987 to 2009 . Women born in even years were invited annually, and those born in odd years, triennially. Attendance for the national mammography screening in 1992-2009 was excellent (86.7\% compliance). This situation provided the opportunity for us to evaluate the screening effect in younger (40-49 years) and older (60-74 years) age groups (Klemi et al, 2003; Immonen-Räihä et al, 2005; Parvinen et al, 2006, 2011).

The Finnish Cancer Registry (FCR) registers all incident cancer cases and all deaths from cancer since 1953 (Anttila et al, 2008; Sarkeala et al, 2008b; Finnish Cancer Registry, 2014). Coding of death from cancer is based on regular linkages between incidence records of the FCR and the death certificates registered by Statistics Finland. For the period 1976-2009, the study material consisted of the data on all invasive BCs (first primary BC) among women aged 40-84 years. There were 3890 in situ BCs, which were excluded from the mortality analysis, but shown separately (Table 3). Most of the in situ cancers (CIS) were of the ductal type (DCIS).

The material was divided into the following subcategories for analysis:

1. Residence: analyses were made for the city of Turku (TKU), Helsinki (HEL) and the rest of Finland (RoF). Helsinki is the most populated and urbanized residential area in Finland and has the most background factors contributing to $\mathrm{BC}$ risk: higher alcohol consumption (Addictionlink, 2014), higher use of hormonal replacement therapy (Salmi et al, 2004) and less favourable reproductive risk factors (Statistics Finland, 2014). The separation of Helsinki from the rest of Finland (covering all rural areas) was made to compare the city of Turku with these two different types of residential areas.

2. Age group at time of $B C$ diagnosis and at $B C$ death: analyses were made for the age groups 40-49, 50-59, 60-74 and 75-84 years. Analysis by age at incidence corresponded to the difference in the screening invitation programme in Turku and other residential areas and the postscreening age group. Owing to a long period of time between the incidence date and death, it was essential to describe the impact of mortality also by the age at death. This analysis produced additional information on the potential benefit of screening by age group with regard to the optimum age of screening and the risk of death from BC. It was also possible to avoid the bias caused by the lead-time. These long-term effects gave a strong cause for including a late screening age group (75-84 years) in the analyses.

3. Time of diagnosis: the data were analysed separately for diagnoses made 1976-1986, 1987-1997 and 1998-2009. The first period represents the period just before the start of screening (prescreening era), the two others the periods after the start of screening invitations (first and second screening periods). The second screening period represents the continuation of the screening programme, which allowed observation of long-term consequences of the screening invitation programme and changes in the most recent period due to factors other than the screening programme itself.

The total incidence and mortality (per 100000 ) were calculated for each residential area by age (1-year intervals) and calendar year. All primary invasive $\mathrm{BC}$ cases and $\mathrm{BC}$ deaths were included until the end of follow-up (31 December, 2009). The aggregated dynamic cohort data covered thus the three residential areas by calendar period and age group. The data of all screening periods (1987-1997, 1998-2009) were combined for final analyses.

Altogether, 40.7 million women-years were included in this study. During the three study periods, there were 83497 invasive BCs and 17508 BC deaths. The number of BCs and BC deaths in each residential area and for each time period is shown in Table 1.

Statistical methods. To maximise the precision of the estimates, differences in the incidence and IBM between the residential areas were analysed by age group and calendar period with Poisson's regression. Appropriate adjustments were made for the underlying differences in the prescreening era (1976-1986) regarding the effectiveness of breast cancer screening policies, age-specific differences in the incidence and IBM among the residential areas during the screening period (1987-2009). The changes in IBM within each residential area were also analysed; for this, IBM was restricted to 10 years in each calendar period. The differences in IBM changes between the residential areas were tested with Wald's test.

The cumulative incidence was calculated by summing the observed one-year age-specific incidence rates for ages 40-84 for the calendar periods 1976-1986 and 1998-2009.

Stata release 12 (StataCorp, Brazos Valley, TX, USA) was used for running the statistical calculations.

Ethics. The Ethics Committee of the Hospital District of Southwest Finland approved the study and authorisation was obtained from the Finnish Ministry of Social Affairs and Health to use the hospital records for data retrieval.

\section{RESULTS}

Incidence. The incidence profiles changed after the start of the screening programmes when the years 1987-1997 and 1998-2009 
Table 1. Crude incidence figures of reported patients with breast cancer (BC), number of deaths from $B C$ and incidence related to the number of follow-up years

\begin{tabular}{|c|c|c|c|c|c|c|c|c|c|c|c|c|}
\hline & \multicolumn{4}{|c|}{ HELSINKI } & \multicolumn{4}{|c|}{ TURKU } & \multicolumn{4}{|c|}{ Rest of Finland (RoF) } \\
\hline & 1976-1986 & 1987-1997 & 1998-2009 & Total & 1976-1986 & 1987-1997 & 1998-2009 & Total & 1976-1986 & 1987-1997 & 1998-2009 & Total \\
\hline \multicolumn{13}{|c|}{ BC cases } \\
\hline $40-49$ & 467 & 789 & 851 & 2107 & 129 & 226 & 237 & 592 & 2625 & 4874 & 5975 & 13474 \\
\hline $50-59$ & 625 & 915 & 1581 & 3121 & 163 & 312 & 429 & 904 & 3189 & 5943 & 10860 & 19992 \\
\hline $60-74$ & 1086 & 1213 & 1952 & 4251 & 303 & 433 & 601 & 1337 & 5179 & 7140 & 11977 & 24296 \\
\hline $75-84$ & 543 & 663 & 794 & 2000 & 142 & 175 & 237 & 554 & 2271 & 3624 & 4974 & 10869 \\
\hline Total & 2721 & 3580 & 5178 & 11479 & 737 & 1146 & 1504 & 3387 & 13264 & 21581 & 33786 & 68631 \\
\hline \multicolumn{13}{|c|}{$B C$ deaths } \\
\hline $40-49$ & 58 & 78 & 71 & 207 & 16 & 28 & 17 & 61 & 308 & 575 & 476 & 1359 \\
\hline $50-59$ & 112 & 177 & 203 & 492 & 37 & 46 & 51 & 134 & 718 & 1134 & 1548 & 3400 \\
\hline $60-74$ & 237 & 369 & 429 & 1035 & 58 & 83 & 98 & 239 & 1279 & 2060 & 2395 & 5743 \\
\hline $75-84$ & 131 & 245 & 290 & 666 & 38 & 70 & 72 & 180 & 745 & 1386 & 1870 & 4001 \\
\hline Total & 538 & 869 & 993 & 2400 & 149 & 227 & 238 & 614 & 3050 & 5155 & 6289 & 14494 \\
\hline \multicolumn{13}{|c|}{ Women-years } \\
\hline $40-49$ & 348304 & 462942 & 497866 & 1309112 & 109289 & 138386 & 137773 & 385448 & 2674393 & 3589935 & 3921929 & 10186257 \\
\hline 50-59 & 336439 & 337265 & 497444 & 1171147 & 114369 & 105718 & 150890 & 370977 & 2631119 & 2658914 & 3923973 & 9214005 \\
\hline $60-74$ & 478027 & 421140 & 483917 & 1383084 & 153905 & 154213 & 166317 & 474435 & 3307016 & 3539803 & 4127346 & 10974165 \\
\hline $75-84$ & 176057 & 207262 & 219001 & 602319 & 52899 & 69879 & 86117 & 208894 & 1081434 & 1448074 & 1899592 & 4429099 \\
\hline Total & 1338826 & 1428609 & 1698227 & 4465661 & 430462 & 468195 & 541096 & 1439753 & 9693960 & 11236725 & 13872839 & 34803524 \\
\hline \multicolumn{13}{|c|}{ BC incidence (Cases/women yrs *100 000) } \\
\hline $40-49$ & 134.1 & 170.4 & 170.9 & & 118.0 & 163.3 & 172.0 & & 98.2 & 135.8 & 152.4 & \\
\hline 50-59 & 185.8 & 271.3 & 317.8 & & 142.5 & 295.1 & 284.3 & & 121.2 & 223.5 & 276.8 & \\
\hline $60-74$ & 227.2 & 288.0 & 403.4 & & 196.9 & 280.8 & 361.4 & & 156.6 & 201.7 & 290.2 & \\
\hline $75-84$ & 308.4 & 319.9 & 362.6 & & 268.4 & 250.4 & 275.2 & & 210.0 & 250.3 & 261.9 & \\
\hline Total $^{\mathbf{a}}$ & 185.4 & 241.4 & 287.8 & & 156.1 & 239.0 & 262.8 & & 127.4 & 187.0 & 232.3 & \\
\hline
\end{tabular}
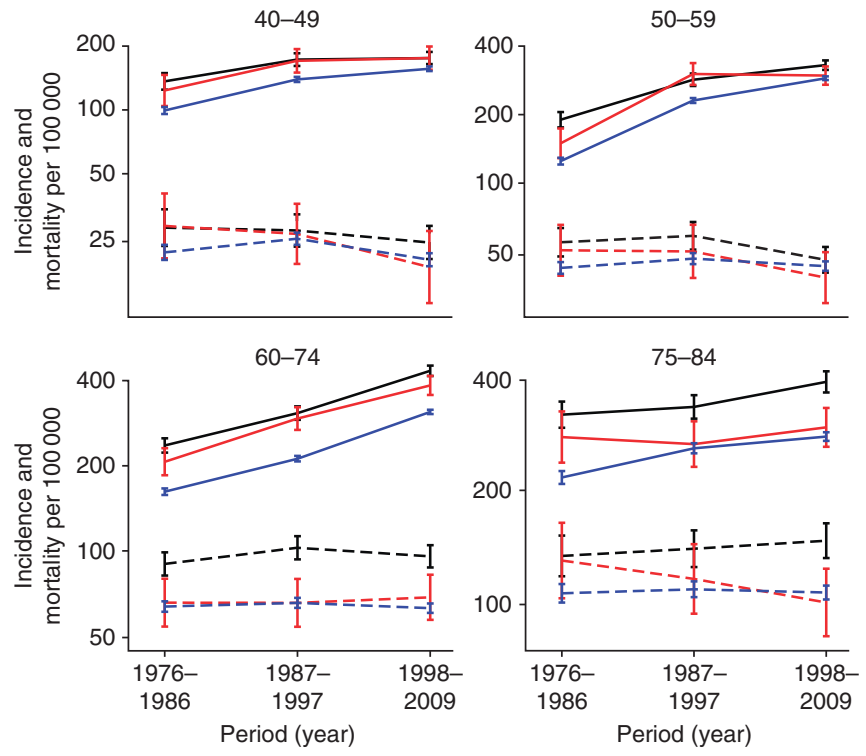

Figure 1. Breast cancer (BC) incidence and mortality per 100000 women-years in three Finnish residential areas; four age groups and three calendar periods from 1976-2009 are included. The dashed lines underneath show mortality for the three periods, the solid lines show the incidence of $\mathrm{BC}$. Helsinki $(\mathrm{HEL})=$ black, Turku $(\mathrm{TKU})=$ red and the rest of Finland $($ RoF) $=$ blue (log scale).

were compared (Figure 1). The influence of the rapid screening start in Turku was evident during the period 1987-1997, but the incidence rose further between 1998 and 2009.

The rise occurred most prominently in the two younger age groups: the incidence in Helsinki was reached compared with Turku and temporally surpassed, whereas the increase in the age group 60-74 years was more stable. There was a decreasing trend in the oldest (postscreening) age group of 75-84 years, which deviated in Turku from Helsinki, and was similar to that found for the rest of the country (See Figure 1).

Figure 2 shows the cumulative BC incidence, until the age of 84 , before the start of the screening (1976-86 dashed lines) and during the second screening period (1998-2009, solid lines). During both time periods, the incidence for RoF remained the lowest and for Helsinki the highest. In Turku, the cumulative incidence increased by $154 \%$ from 0.0826 in the prescreening era of $1976-1986$ to 0.1269 in the second screening period, of 1998-2009. The corresponding values and percentages were 0.0673 and 0.1124 (increase 167\%) for RoF and 0.0975 and 0.1466 (increase 150\%) for Helsinki, respectively.

The relations in the rate ratios (RRs) for the crude results of the prescreening era (1976-86) and screening period (1987-2009) are shown in Table 2. It also shows that before the start of screening the $\mathrm{BC}$ incidence in all age groups was higher in Turku than in the $\mathrm{RoF}$, and correspondingly in all the age groups the $\mathrm{BC}$ incidence was lower in Turku than in Helsinki.

After the start of screening, during 1987-2009, the relative decrease in breast cancer incidence in Turku's oldest age group (75-84 years) was significantly larger, by $20 \%$, compared with the RoF (Table 4). In the 60- to 74-year-age group, the differences remained unchanged, whereas, among the younger age groups, Turku reached the same level as Helsinki. In the 40- to 49-year and the 50-59-year-age groups, the increase in the incidence of $\mathrm{BC}$ was 12 and $26 \%$, respectively.

CIS percentages are shown in Table 3. There were 3890 in situ breast carcinomas registered, which corresponded to $4.7 \%$ of all cancer cases. After the start period of screening, in situ carcinomas were diagnosed more frequently. In the 50- to 59-year-age group that was screened throughout the country, the CIS percentage was the highest in Helsinki (11.9\%) and in RoF (9.4\%) during 19982009. In the youngest (40-49) and oldest screened (60-74) age 
groups, Turku had the highest incidence of in situ carcinomas, $10.2 \%(1987-1997)$ and 9.5\% (1998-2009), respectively.

Mortality. Before the start of screening (1976-1986), BC mortality in Turku was similar to the reference city, Helsinki, in the 40 - to 49-year and 75- to 84-year age groups. Compared with the RoF, it was higher in all age groups (Figure 1). In the 50- to 59-year age group, mortality in Turku was intermediate between the two other residential areas. After screening start, mortality sank in the three age groups in Turku; in the 60- to 74-year age group, the already low mortality was nearly unchanged.

The incidence-based mortality was calculated taken into account the underlying IBM in the prescreening era for each age group at

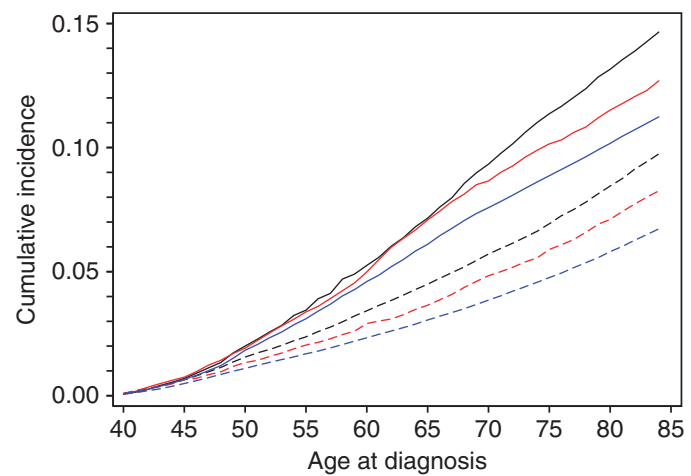

Figure 2. Cumulative BC incidence for patients aged up to 84 years. The dashed lines underneath show the situation at the period before start of the screening programs (1976-1986) and the solid lines show the situation during the latter screening period, 1998-2009. Helsinki $(H E L)=$ black, Turku $(T K U)=$ red and the rest of Finland $($ RoF $)=$ blue. diagnosis and at death. In Turku, a statistically significant decrease of $>20 \%$ in the IBM took place between 1987 and 2009 in the 60to 74-year age group at diagnosis compared with Helsinki (IBMRR: $0.75,95 \%$ CI: $0.57-1.00, P<0.05)$ and in the 75 - to 84 -year age group at death compared with RoF (IBMRR: 0.72, 95\% CI: $0.53-$ 0.96) (Table 4).

We studied changes in the IBM over time and within each residential area for completeness also by 10 -year IBM. These data showed that the 10-year IBM, based on age group at death, decreased during the first screening period (1987-1997) compared with the prescreening era and was different between the residential areas $(P=0.037)$ in the 75 - to 84 -year age group. In Turku, this decline was $44 \%$ (IBMRR: 0.56, 95\% CI: 0.38-0.83).

Because the 40- to 49-year age group was only screened in Turku, Turku was considered a unique study area. The largest decline in 10-year IBM occurred also in this age group between 1998 and 2009: 51\% at diagnosis (IBMRR: 0.49, 95\% CI: 0.27-0.91) and 59\% at death (IBMRR: 0.41, 95\% CI: 0.18-0.91). The estimated effect of screening in Turku in this age group varied from 0.73 (95\% CI: $0.50-1.06)$ to 0.97 (0.64-1.47), depending on the region used for comparisons (Table 4).

\section{DISCUSSION}

The effect of the early start and execution of the Turku mammography screening programme compared with other residential areas lead to an increase in the incidence of BC in the 40- to 74-year age group of women undergoing mammography screening from the first to the second time period, that is, from 1976-1986 to 1987-1997, after which it returned to starting level by 1998-2009 (Table 1).

Table 2. Crude age-specific breast cancer (BC) incidence rate ratios (IRRs) and incidence-based mortality rate ratios (IBMRRs) with $\mathbf{9 5 \%}$ confidence intervals in Turku (TKU) in comparison with the rest of Finland (RoF) and Helsinki (HEL)

\begin{tabular}{|c|c|c|c|}
\hline & Incidence & $\begin{array}{l}\text { BC-related risk of mortality } \\
\text { by year of diagnosis }\end{array}$ & $\begin{array}{l}\text { BC-related risk of mortality } \\
\text { by year of death }\end{array}$ \\
\hline \multicolumn{4}{|l|}{ TKU vs RoF } \\
\hline \multicolumn{4}{|l|}{$40-49$} \\
\hline 1976-1986 & $1.20 *(1.01-1.44)$ & $1.24(0.93-1.65)$ & $1.48(0.97-2.25)$ \\
\hline 1987-2009 & $1.16^{\star \star}(1.06-1.27)$ & $0.90(0.71-1.16)$ & $1.08(0.77-1.53)$ \\
\hline \multicolumn{4}{|l|}{$50-59$} \\
\hline 1976-1986 & $1.18^{*}(1.00-1.38)$ & $1.08(0.85-1.37)$ & $1.13(0.86-1.49)$ \\
\hline 1987-2009 & $1.13^{\star \star \star}(1.06-1.22)$ & $1.06(0.86-1.30)$ & $0.89(0.71-1.11)$ \\
\hline \multicolumn{4}{|l|}{$60-74$} \\
\hline 1976-1986 & $1.26^{\star \star \star}(1.12-1.41)$ & $1.09(0.90-1.32)$ & $1.02(0.84-1.24)$ \\
\hline 1987-2009 & $1.29 \star \star \star ~(1.22-1.38)$ & $0.94(0.79-1.11)$ & $0.98(0.83-1.16)$ \\
\hline \multicolumn{4}{|l|}{$75-84$} \\
\hline $1976-1986$ & 1.28 ** $(1.08-1.51)$ & $1.05(0.79-1.40)$ & $1.21(0.97-1.50)$ \\
\hline $1987-2009$ & $1.03(0.93-1.14)$ & $0.77(0.59-1.00)$ & $0.86(0.71-1.05)$ \\
\hline \multicolumn{4}{|l|}{ TKU vs HEL } \\
\hline \multicolumn{4}{|l|}{$40-49$} \\
\hline 1976-1986 & $0.88(0.72-1.07)$ & $0.85(0.62-1.17)$ & $1.04(0.65-1.67)$ \\
\hline 1987-2009 & $0.98(0.89-1.09)$ & $0.83(0.63-1.09)$ & $0.98(0.66-1.44)$ \\
\hline \multicolumn{4}{|l|}{$50-59$} \\
\hline 1976-1986 & $0.77^{\star \star}(0.65-0.91)$ & $0.75^{\star}(0.58-0.98)$ & $0.90(0.66-1.22)$ \\
\hline 1987-2009 & $0.97(0.89-1.05)$ & $0.82(0.65-1.03)$ & $0.83(0.66-1.07)$ \\
\hline \multicolumn{4}{|l|}{$60-74$} \\
\hline 1976-1986 & $0.87 *(0.76-0.98)$ & $0.84(0.68-1.04)$ & $0.68^{\star \star \star}(0.55-0.85)$ \\
\hline 1987-2009 & $0.92 *(0.86-0.99)$ & $0.64^{\star \star \star}(0.53-0.77)$ & $0.65^{\star \star \star}(0.54-0.78)$ \\
\hline \multicolumn{4}{|l|}{$75-84$} \\
\hline 1976-1986 & $0.87(0.72-1.05)$ & $0.89(0.65-1.22)$ & $0.89(0.69-1.13)$ \\
\hline 1987-2009 & $0.77^{\star \star \star}(0.69-0.86)$ & $0.64^{\star \star}(0.47-0.85)$ & $0.67^{\star \star \star}(0.54-0.84)$ \\
\hline
\end{tabular}


Table 3. In situ breast cancer (\% of all BC cases in three residential areas, 1976-2009)

\begin{tabular}{|c|c|c|c|c|c|c|c|c|c|c|c|c|}
\hline & \multicolumn{4}{|c|}{ HELSINKI } & \multicolumn{4}{|c|}{ TURKU } & \multicolumn{4}{|c|}{ Rest of Finland (RoF) } \\
\hline & 1976-1986 & 1987-1997 & 1998-2009 & Total & $1976-1986$ & 1987-1997 & 1998-2009 & Total & 1976-1986 & 1987-1997 & 1998-2009 & Total \\
\hline \multicolumn{13}{|c|}{ Numbers (percentages) } \\
\hline $40-49$ & $68(1.3)$ & $37(4.7)$ & $77(9.0)$ & $120(5.7)$ & $0(0.0)$ & $23(10.2)$ & $23(9.7)$ & $46(7.8)$ & $59(2.2)$ & $180(3.7)$ & $347(5.8)$ & $586(4.3)$ \\
\hline $50-59$ & $4(0.6)$ & $37(4.0)$ & 188 (11.9) & $229(7.3)$ & $2(1.2)$ & $15(4.8)$ & 34 (7.9) & $51(5.6)$ & $36(1.1)$ & $296(5.0)$ & $1022(9.4)$ & 1354 (6.8) \\
\hline $60-74$ & $6(0.6)$ & $20(1.6)$ & $149(7.6)$ & $175(4.1)$ & $0(0.0)$ & $22(5.1)$ & $57(9.5)$ & $79(5.9)$ & $20(0.4)$ & $156(2.2)$ & $822(6.9)$ & $998(4.1)$ \\
\hline $75-84$ & $0(0.0)$ & $12(1.8)$ & $36(4.5)$ & $48(2.4)$ & $0(0.0)$ & $2(1.1)$ & $8(3.4)$ & $10(1.8)$ & $1(0.0)$ & 40 (1.1) & $153(3.1)$ & $194(1.8)$ \\
\hline Total & $16(0.6)$ & $106(3.0)$ & $450(8.7)$ & $572(5.0)$ & $2(0.3)$ & $62(5.4)$ & $122(8.1)$ & $186(5.5)$ & $116(0.9)$ & $672(3.1)$ & 2344 (6.9) & $3132(4.6)$ \\
\hline \multicolumn{13}{|c|}{ Numbers of in situ BC per 1000000 woman-years } \\
\hline & 1.2 & 7.4 & 26.5 & 12.8 & 0.5 & 13.2 & 22.5 & 12.9 & 1.2 & 6.0 & 16.9 & 9.0 \\
\hline
\end{tabular}

Table 4. Adjusted age-specific BC RRs and IBMRRs with $95 \%$ confidence intervals in Turku (TKU) in comparison with the rest of Finland (RoF) and Helsinki (HEL)

\begin{tabular}{|c|c|c|c|}
\hline & Incidence & $\begin{array}{c}\text { BC-related risk of mortality } \\
\text { by year of diagnosis }\end{array}$ & $\begin{array}{c}\text { BC-related risk of mortality } \\
\text { by year of death }\end{array}$ \\
\hline \multicolumn{4}{|c|}{ TKU vs RoF } \\
\hline $40-49$ & $0.97(0.79-1.17)$ & $0.73(0.50-1.06)$ & $0.73(0.42-1.27)$ \\
\hline $50-59$ & $0.96(0.81-1.14)$ & $0.98(0.71-1.35)$ & $0.78(0.55-1.12)$ \\
\hline $60-74$ & 1.03 (0.90-1.17) & $0.85(0.66-1.10)$ & $0.96(0.74-1.25)$ \\
\hline $75-84$ & $0.80 *(0.66-0.98)$ & $0.78(0.54-1.12)$ & $0.72 *(0.53-0.96)$ \\
\hline \multicolumn{4}{|c|}{ TKU vs HEL } \\
\hline $40-49$ & $1.12(0.89-1.39)$ & $0.97(0.64-1.47)$ & $0.94(0.51-1.72)$ \\
\hline $50-59$ & $1.26^{*}(1.04-1.52)$ & $1.08(0.76-1.54)$ & $0.93(0.63-1.38)$ \\
\hline $60-74$ & $1.06(0.92-1.23)$ & $0.75^{*}(0.57-1.00)$ & $0.94(0.71-1.25)$ \\
\hline $75-84$ & $0.89(0.72-1.10)$ & $0.76(0.51-1.13)$ & $0.76(0.55-1.06)$ \\
\hline
\end{tabular}

Reproductive factors (early menarche and age at first full-term pregnancy), lifestyle (alcohol consumption and obesity), an urban environment and hormonal factors (especially hormone replacement therapy) affect the $\mathrm{BC}$ incidence. Changes in the impact of these risk factor changes in Finland, as in most developed countries, explain the continuous increase in $\mathrm{BC}$ incidence of $\mathrm{BC}$ during the last decades. This rising trend took place in all residential areas.

It is important to observe that the relatively high occurrence of invasive breast cancer in the Turku population was not due to overdiagnosis caused by screening (Figure 2, Table 1). Comparisons between Turku and the reference residential areas did not show any consistent excess of BC diagnoses in Turku. These results are in line with the European estimates of overdiagnosis due to screening, which range from 1 to $10 \%$ (Duffy et al, 2010; Puliti et al, 2012; Lund et al, 2013; Heinävaara et al, 2014). Overdiagnosis of $5-7 \%$ has occured among women aged 50 to 74 years who have been targeted for breast cancer screening at age 50-59 (Heinävaara et al, 2014). Thus, we cannot rule out a small amount of overdiagnosis in breast cancer screening in general.

The numbers of CIS of the breast increased in all residential areas and age groups in parallel with mammography screening frequency. The increases in the number of CIS are probably partially a consequence of overdiagnosis, and our results corroborate this (Miller et al, 2002; Moss, 2005; Zackrisson et al, 2006). There are no reliable methods available to predict which patients with CIS will have invasive BC (Allen et al, 2014). At present, the increasing number of CIS due by mammography screening must be accepted. CIS poses, however, a real threat to the patient: if left untreated CIS may often progress into invasive cancer (Duffy et al, 2005), even despite complete local excision. Indeed, $30 \%$ of patients whose CIS has been excised will have a recurrence within 10 years (Cuzick et al, 2011).

The significant reduction in mortality due to $\mathrm{BC}$ of screened subjects compared with non-screened subjects has been confirmed in several studies (Fielder et al, 2004; Allgood et al, 2008; Roder et al, 2008; Nickson et al, 2012; Puliti and Zappa, 2012; Otto et al, 2012; Hofvind et al, 2013).

A mortality reduction of at least $20 \%$ among invited to screening $v s$ non-invited has also been reported by Sarkeala et al (2008a) and Tabár et al (2011) and recently by Weedon-Fekjaer et al (2014). In the present study, a corresponding benefit for screened persons regarding BC mortality was documented for 25 to $28 \%$. These results are also in line with our previous reports on the survival (Klemi et al, 2003; Immonen-Räihä et al, 2005) and mortality (Parvinen et al, 2006) of patients with BC.

The estimated effect of screening in Turku in the age group of 40 to 49 years varied from 3 to $27 \%$ in terms of adjusted IBM results depending on the region the results for Turku are compared (Table 4). Thus, we cannot rule out that there was a real decline in IBM in the youngest invited age group in Turku, but the limited population size and the low number of deaths from BC in this age group weaken the statistical power. Screening of the youngest age group started to decrease gradually in 2000 in Turku and levelled off by 2009. This may also dilute incidence and mortality results among the youngest screening participants.

In a previous study in this youngest age group in Turku, there were no differences in the incidence of $\mathrm{BC}$ or IBM between the women who were invited for screening annually or triennially. Because of the lack of a control group (no screening), it was not possible to determine whether this result was due to a reduction in effects of mammography screening of this age group or whether the effectiveness of triennial screening is similar to that of annual screening (Parvinen et al, 2011). However, in this study, among the youngest (premenopausal) group, a $>50 \%$ decline in the IBM (10 years follow-up restriction) occurred both in the age group at diagnosis and at death in Turku. These results are in accordance with Italian (Gorini et al, 2004), Icelandic (Gabe et al, 2007) and Swedish (Hellquist et al, 2011) results and give further support to our previous results regarding survival (Klemi et al, 2003). 
The decline in BC mortality in all age groups started in Finland in the late 1980s (NORDCAN database, 2014), as in many other developed countries (Siegel et al, 2012; GLOBOCAN 2012, 2014). In this study, this decline occurred among all age groups and in all residential areas. An obvious explanation for this beneficial trend is the global improvement in treating BC (Youlden et al, 2012). This effect seems to be evident, especially in the 40- to 49-year age group (Figure 1).

The effects of screening became less discrepant in terms of 1998-2009. First, the screening programmes became standardized during the last calendar period, and, second, the effect of improved therapy had an impact on all residential areas. Nevertheless, the follow-up of women diagnosed in the second screening period (1987-1997) was brief and this may affect the results.

Our database is huge and includes some 40 million womenyears over more than 20 years. The participation in mammography screening in Finland was excellent-the rate was $86.7 \%$ during 1992-2009 (Sarkeala et al, 2013). These factors increase the validity of the results. The results are drawn from homogenous, multiresidential areas and age groups with known prognostic background variables, but at the same time with similar treatments and participation rates. These types of results with urbanized (Helsinki) and unurbanized (RoF) references may also be considered more reliable than study results drawn from nonhomogeneous populations vulnerable to bias (Zahl et al, 2004; Autier et al, 2011; Bleyer and Welch, 2012; Gøtzsche et al, 2012).

Owing to the multi-dimensional changes in the incidence and treatment of $\mathrm{BC}$ over the last decades, it is not straightforward to draw conclusions concerning the effectiveness of mammography screening programmes. These multi-dimensional changes interact strongly with mammography screening efficacy. Obviously, continuous long-term monitoring of the morbidity and mortality of patients with BC will be needed also in the future (Ursin, 2012).

The wide mammography screening programme in Turku was an effective and long-standing tool to decrease mortality in elderly age groups. The screening programme did not lead to any significant increase in the number of invasive breast cancers in any of the age groups (that is, overdiagnosis) compared with the other residential areas. On the basis of all available data, we have no other consistent explanation for the decrease in mortality among the elderly women in Turku than screening. While there was a clear decline in IBM in all regions in the 40- to 49-year age group, this decline was the largest in the youngest age group in Turku, although it did not reach statistical significance compared with the other regions.

Continuous and practical clinical study results such as the ones of this study are urgently needed in for example, the light of the ongoing discussion on epidemiological methodology (Signeurin et al, 2011; Ursin, 2012). The strength of this study was the long follow-up period, two different broad residential population comparison areas within the same country, as well as the opportunity to adjust the results with the 11-year period before the screening start. The results of this study provide evidence that unnecessary BC deaths in other parts of Finland could be avoided by using the Turku-based screening framework. The crucial elements in the Turku City were to invite both the younger and older age groups for mammography screening for getting the optimal life span BC mortality decline among women population. Taking into account the increasing life expectancy of women, these results support that mammography screening should be extended from age 50 to 74 years.

\section{ACKNOWLEDGEMENTS}

We thank Robert M. Badeau and Robert Paul for editing the language of this manuscript.

\section{CONFLICT OF INTEREST}

The authors declare no conflict of interest.

\section{REFERENCES}

Addictionlink (2014) Alcohol use in Finland. Available from URL http:// www.paihdelinkki.fi/articles/111-alcohol-use-in-finland (in Finnish) [accessed July 6].

Allen MD, Thomas GJ, Clark S, Dawoud MM, Vallat S, Payne SJ, Gomm JJ, Dreger SA, Dickinson S, Edwards DR, Pennington CJ, Sestak I, Cuzick J, Marshall JF, Hart IR, Jones JL (2014) Altered microenvironment promotes progression of preinvasive breast cancer: myoepithelial expression of $\alpha \mathrm{v} \beta 6$ integrin in DCIS identifies high-risk patients and predicts recurrence. Clin Cancer Res 20: 344-357.

Allgood PC, Warwick J, Warren RML, Day NE, Duffy SW (2008) A case-control study of the impact of the East Anglian breast screening programme on breast cancer mortality. Br J Cancer 98: 206-209.

Anttila A, Sarkeala T, Hakulinen T, Heinävaara S (2008) Impacts of the Finnish service screening programme on breast cancer rates. BMC Public Health 8: 38.

Autier P, Boniol M, Gavin A, Vatten LJ (2011) Breast cancer mortality in neighboring European cancers with different levels of screening but similar access to treatment: trend analysis of WHO mortality database. BMJ 343: d441.

Autier P, Boniol M, LaVecchia C, Vatten L, Gavin A, Hénry C, Heanue M (2010) Disparities in breast cancer mortality trends between 30 European countries: retrospective trend analysis of WHO mortality database. BMJ 341: c3620.

Bleyer A, Welch HG (2012) Effect of three decades of screening mammography on breast-cancer incidence. N Engl J Med 367: 1998-2005.

Broeders M, Moss S, Nyström L, Njor S, Jonsson H, Paap E, Massat N, Duffy S, Lynge E, Paci E. Euroscreen Working Group (2012) The impact of mammographic screening on breast cancer mortality in Europe: a review of trend studies. J Med Screen 19: 14-25.

Coleman MP, Forman D, Bryant H, Butler J, Rachet B, Maringe C, Nur U, Tracey E, Coory M, Hatcher J, MvGahan CE, Turner D, Marrett L, Gjerstorff ML, Johannesen TB, Adolfsson J, Lambe M, Lawrence G, Meechan D, Morris EJ, Middleton R, Steward J, Richards MA. ICBP Module 1 Working Group (2011) Cancer survival in Australia, Canada, Denmark, Norway, Sweden, and the UK, 1995-2007. (The International Cancer Benchmarking Partnership): an analysis of population-based cancer registry data. Lancet 377: 127-138.

Cuzick J, Sestak I, Pinder SE, Ellis IO, Forsyth S, Bundred NJ, Forbes JF, Bishop H, Fentiman IS, George WD (2011) Effect of tamoxifen and radiotherapy in women with locally excised ductal carcinoma in situ: long-term results from the UK/ANZ DCIS trial. Lancet Oncol 12: 21-29.

Duffy SW, Agbaje O, Tabár L, Vitak B, Bjurstam N, Björneld L, Myles JP, Warwic J (2005) Estimates of overdiagnosis from two trials of mammographic screening for breast cancer. Breast Cancer Res 7: 258-265.

Duffy SW, Tabar L, Olsen AH, Vitak B, Allgood PC, Chen TH, Yen AM, Smith RA (2010) Absolute numbers of lives saved and overdiagnosis in breast cancer screening, from a randomized trial and from the Breast Screening Programme in England. J Med Screen 17: 25-30.

Fielder HM, Warwick J, Brook D, Gower-Thomas K, Cuzick L, Monypenny I, Duffy SW (2004) A case-control study to estimate the impact on breast cancer death of the breast screening programme in Wales. J Med Screen 11: 194-198.

Finnish Cancer Registry (2014) Cancer research and statistics information. Available from URL https://cancer-fi.directo.fi/syoparekisteri/en/ ?x56215626=99682018 (in Finnish) [accessed April 14].

Gabe R, Tryggvadottir L, Sigfusson BF, Olafsdóttir GH, Sigurdsson K, Duffy SW (2007) A case-control study to estimate the impact of the Icelandic population-based mammography screening program on breast cancer death. Acta Radiol 48: 948-955.

GLOBOCAN 2012 (2014) Estimated cancer incidence, mortality and prevalence worldwide in 2012. Available from URL globocan.iarc.fr [accessed April 14].

Gorini G, Zappa M, Miccinesi G, Paci E, Costantini AS (2004) Breast cancer mortality trends in two areas of the province of Florence, Italy, where screening programs started in the 1970 and 1990s. Br J Cancer 90: 1780-1783. 
Gøtzsche PC, Jørgensen KJ, Zahl PH, Maehlen J (2012) Why mammography screening has not lived up to expectations from the randomised trials. Cancer Causes Control 23: 15-21.

Heinävaara S, Sarkeala T, Anttila A (2014) Overdiagnosis due to breast cancer screening: updated estimates of the Helsinki service study in Finland. Br J Cancer 111: 1463-1468.

Hellquist BN, Duffy SW, Abdsaleh S, Björneld L, Bodás P, Tabár L, Viták B, Zackrisson S, Nyström L, Jonsson H (2011) Effectiveness of populationbased service screening with mammography for women ages 40 to 49 years: evaluation of the Swedish mammography screening in Young Women (SCRY) cohort. Cancer 117: 714-722.

Hofvind S, Ursin G, Tretli S, Sebuødegård S, Møller B (2013) Breast cancer mortality in participants of the Norwegian breast cancer screening program. Cancer 119: 3106-3112.

Immonen-Räihä P, Kauhava L, Parvinen I, Holli K, Kronqvist P, Pylkkänen L, Helenius H, Kaljonen A, Räsänen O, Klemi PJ (2005) Mammographic screening reduces risk of breast carcinoma recurrence. Cancer 103: $474-482$.

Independent UK Panel on Breast Cancer Screening (2012) The benefits and harms of breast cancer screening: an independent review. Lancet 380: 1778-1786.

Klemi PJ, Parvinen I, Pylkkänen L, Kauhava L, Immonen-Räihä P, Räsänen O, Helenius H (2003) Significant improvement in breast cancer survival through population-based mammography screening. Breast 12: 308-313.

Lund E, Mode N, Wasseth M, Thalabard JC (2013) Overdiagnosis of breast cancer in the Norwegian Breast Cancer Screening Program estimated by the Norwegian Women and Cancer cohort study. BMC Cancer 13: 614.

Miller AB, To T, Baines CJ, Wall C (2002) The Canadian National Breast Screening Study-1: breast cancer mortality after 11 to 16 years of follow-up. A randomized screening trial of mammography in women age 40 to 49 years. Ann Intern Med 137: 305-312.

Monticciolo D, Monsees B (2013) Effect of screening mammography on breast cancer incidence (correspondence). N Engl J Med 367: 677-679.

Moss S (2005) Overdiagnosis and overtreatment of breast cancer: overdiagnosis in randomised controlled trials of breast cancer screening. Breast Cancer Res 7: 230-234.

Moss SM, Nyström L, Jonsson H, Paci E, Lynge E, Njor S, Broeders M. (Euroscreen Working Group) (2012) The impact of mammographic screening on breast cancer mortality in Europe: a review of trend studies. J Med Screen 19: 26-32.

Nickson C, Mason KE, English DR, Kavanagh AM (2012) Mammographic screening and breast cancer mortality: a case-control study and metaanalysis. Cancer Epidemiol Biomarkers Prev 21: 1479-1488.

NORDCAN database (2014) Nordic tool for cancer information. Available from URL http://www-dep.iarc.fr/NORDCAN/english/frame.asp [accessed April 14].

Otto SJ, Fracheboud J, Verbeek AL, Boer R, Reijerink-Verheij JC, Otten JD, Broders MJ, de Koning HJ (2012) Mammography screening and risk of breast cancer death: a population-based case-control study. Cancer Epidemiol Biomarkers Prev 21: 66-73.

Parvinen I, Chiu S, Pylkkänen L, Klemi P, Immonen-Räihä P, Kauhava L, Malila N, Hakama M (2011) Effects of annual vs triennial mammography interval on breast cancer incidence and mortality in ages 40-49 in Finland. Br J Cancer 105: 1388-1391.

Parvinen I, Helenius H, Pylkkänen L, Anttila A, Immonen-Räihä P, Kauhava L, Räsänen O, Klemi PJ (2006) Service screening mammography reduces breast cancer mortality among elderly women in Turku. J Med Screen 13: 34-40.
Puliti D, Duffy SW, Miccinesi G, de Koning H, Lynge E, Zappa M, Paci E. Euroscreen Working Group (2012) Overdiagnosis in mammographic screening for breast cancer in Europe: a literature review. J Med Screen 19: $42-56$.

Puliti D, Zappa M. Breast cancer screening: are we seeing the benefit? (2012) BMC Med 10: 106.

Roder D, Houssami N, Farshid G, Gill G, Luke C, Downey P, Beckmann K, Iosifidis P, Grieve L, Williamson L (2008) Population screening and intensity of screening are associated with reduced breast cancer mortality: evidence of efficacy of mammography screening in Australia. Breast Cancer Res Treat 108: 409-416.

Salmi T, Paldán M, Klaukka T (2004) The use of hormone replacement therapy has decreased in all parts of Finland. Finnish Med J 59: 1042-1045.

Sarkeala T, Heinävaara S, Anttila A (2008a) Organised mammography screening reduces breast cancer mortality: a cohort study from Finland. Int J Cancer 122: 614-619.

Sarkeala T, Heinävaara S, Anttila A (2008b) Breast cancer mortality with varying invitational policies in organised mammography. Br J Cancer 98: 641-645.

Sarkeala T, Näveri T, Malila N, Anttila A (2013) Performance of populationbased breast cancer screening in Finland in 1992-2009. Finnish Med J 68: $225-231$.

Sarkeala T (2008) Performance and effectiveness of organised breast cancer screening in Finland. Acta Oncol 47: 1618.

Seigneurin A, Francois O, Labarère J, Oudeville P, Monlong J, Colonna M (2011) Overdiagnosis from non-progressive cancer detected by screening mammography: stochastic simulation study with calibration to population based registry data. BMJ 343: d7017.

Siegel R, Naishadham D, Jemal A (2012) Cancer statistics, 2012. CA Cancer J Clin 62: 10-29.

Statistics Finland (2014) Number of births fell further. Available from URL http://tilastokeskus.fi/til/synt/2013/synt_2013_2014-04-08_tie_ 001_en.html (in Finnish) [accessed July 6].

Tabár L, Vitak B, Chen TH, Yen AM, Cohen A, Tot T, Chiu SY, Chen SL, Fann JC, Rosell J, Fohlin H, Smith RA, Duffy SW (2011) Swedish twocounty trial: impact of mammographic screening on breast cancer mortality during 3 decades. Radiology 260: 658-663.

Ursin G (2012) Mammographic screening debate on study design: a need to move the field forward. BMC Med 10: 164 .

Weedon-Fekjaer H, Romundstad PR, Vatten LJ (2014) Modern mammography screening and breast cancer mortality: population study. BMJ 348: g3701.

Youlden DR, Cramb SM, Dunn NA, Muller JM, Pyke CM, Baade PD (2012) The descriptive epidemiology of female breast cancer: an international comparison of screening, incidence, survival and mortality. Cancer Epidemiol 36: 237-248.

Zackrisson S, Andersson I, Janzon L, Manjer J, Garne JP (2006) Rate of overdiagnosis of breast cancer 15 years after end of Malmö mammographic screening trial: follow-up study. BMJ 331: 689-692.

Zahl PH, Strand BH, Maehlen J (2004) Incidence of breast cancer in Norway and Sweden during introduction of nationwide screening: prospective cohort study. BMJ 328: 921-924.

This work is published under the standard license to publish agreement. After 12 months the work will become freely available and the license terms will switch to a Creative Commons AttributionNonCommercial-Share Alike 4.0 Unported License. 